\title{
Review Paper on Study on Properties of Black Cotton Soil using Stone Dust and Sisal Fiber
}

\author{
Wankhade Ashutosh Purushottam¹, Pratiksha Malviya² \\ ${ }^{1} \mathrm{M}$. Tech. Scholar, ${ }^{2}$ Professor \\ 1,2Department of Civil Engineering, Millennium Institute of Technology \& Science, \\ 1,2Bhopal, Madhya Pradesh, India
}

\begin{abstract}
INTRODUCTION
Soil is basic and important element in Civil Engineering field. Stability of every structure depends on the type and characteristics of foundation which in turn depends on the type of soil. Many problems irrupt if expansive soil, Natural soil is to be used in foundation, because of its shrinkage and swelling properties. There are many methods to make natural soil stable for various constructions. Natural soil is comfortable for road work, compared to other types of soil. There are two ways to enhance the quality of sub grade soil "Replacement of soil" or "Soil stabilization". Soil stabilization can be done chemically or mechanically. Chemical stabilization is carried out by adding different chemicals in suitable proportion, while Mechanical stabilization is achieved by addition of admixtures which helps to improve the properties of soil.
\end{abstract}

\section{Pavement}

Pavement is the flat part of the road on which people and traffic move. Generally, a pavement consists of few layers with different materials. A pavement is, therefore defined as a relatively stable crust constructed over the natural soil for the purpose of supporting and distributing the wheel loads and providing an adequate wearing surface.

\section{Methods of Stabilization}

Currently several methods of soil stabilization are available with their own advantages and disadvantages. The engineer in charge has to decide a method or a combination of methods by considering the soil type, the needed engineering properties to be improved, and the type structure, and economy. Stabilization methods can be broadly classified into two main groups. They are mechanical and chemical. Additionally thermal and electrical methods are also considered on occasions. Important stabilization methods and their suitability are discussed in the following paragraphs.

\section{A. Mechanical Stabilization}

$>$ It is the Process of improving the properties of soil by changing its gradation.

$>$ Two or more natural soils are mixed to obtain a composite material which is superior to any of its components..

> Mechanical stability of soil depends upon plastic characteristics, gradation of mixed soil, degree of compaction attained in the field.

B. Chemical Stabilization

$>$ It is the Stabilization done by adding different chemicals such as calcium chloride, sodium chloride, sodium silicate etc.
$>$ Chemical Stabilization is more expansive than other types of stabilization.

C. Lime Stabilization

$>$ Lime is being used as a soil stabilizer since ancient times.

$>$ The hydrated lime $\mathrm{Ca}(\mathrm{OH})_{2}$ is the most commonly used lime for soil stabilization.

$>$ Lime is also used in combination with other stabilizers such as fly ash and cement.

D Soil plasticity, density and strength are changed by adding lime to soil. Lime increases the plasticity index of low plastic soils and decreases the plasticity index of high plastic soils.

$>$ Almost all types of soils can be stabilized using lime.

D. Cement Stabilization

It is done by pulverized mixing soil and Portland cement with water and compacting the mix to attain a strong material.

D In this stabilization, cement is mixed in a particular range about $5-14 \%$ by volume.

E. Fly ash Stabilization

$>$ Stabilization of soils by using fly ash and mixture of lime or cement and fly ash is gaining more importance in recent times since it has widespread availability.

$>$ This method is inexpensive and takes less time than other stabilization methods. Fly ash may be mixed with soil during excavation right in the field.

\section{F. Rice husk ash Stabilization}

> Rice husk ash stabilization is done by adding Rice husk ash to soil. It is useful for stabilization of clayey soil.

\section{RELATED WORK}

$>$ S. A. Naeini \& R. Ziaie Moayed et al (2009) in their study they prepared three types of soil samples with different percentage of bentonite on which CBR tests were carried with or without geo grid reinforcement in one or multilayer. Result shows that increase in plasticity index decreases the CBR value in both soaked and un soaked condition. CBR can be considerably increased by using geo grid reinforcement in two layers when compared with unreinforced, but less value when compared with single layered reinforcement. By placing geo grid at layer 2 there is a considerable increase in CBR value compared with unreinforced soil in both soaked and un soaked conditions. By using two layers of geo grid at layer 1 and 3, un soaked CBR value increases compared with unreinforced soil. However this increment is much less when compared to the 
case when geo grid is placed at layer 2. Further, the soaked CBR value is higher than the value obtained for both single and no layer of geo grid.

$>$ Dr Sujatha Evangelin Ramani (2012) provide geo grid reinforcement to improve the strength of sub grade and reduce the thickness of the pavement. The author conducted CBR tests on soil with geo grid introduced at different depths within the sample, in single, double and triple layer and found that the best performance in the single layer occurs when geo grid is placed at $2 / 3$ distance from the base. And found that the CBR value of 3 layer of geo grid is lesser than 2 layer but higher than single layer and hence concluded that geo grid increases the strength of sub grade soil in both soaked and un soaked condition and proved that geo grid reinforcement provided in a single or multilayer to the sub grade increases the strength of the soil and thus reduces the thickness of the pavement.

$>$ Pradeep Singh and K. S. Gill (2012) Reinforced soils are often treated as composite materials in with reinforcement resisting tensile stress and interacting with soil through friction. Although there is lot of information and experience with geo-synthetic reinforcement of sub-grade soils, many pavement failures still occur. These failures may be due to lack of understanding of how these materials influence the engineering properties of sub-grade soils and what is the optimum position of reinforcement. Therefore a compressive laboratory program is required to study strength characteristics of both reinforced and un-reinforced sub-grade soils also to investigate their behaviors under cycle leading. The author in his work describes the beneficial effects of reinforcing the sub-grade layer with a single layer of geo-grid at different positions and thereby determination of optimum position of reinforcement layer. The optimum position was determined based on California Bearing Ratio (CBR value) and unconfined compression tests were conducted to decide the optimum position of geo-grid. Through his experimental work he found that by providing geo grid reinforcement at $0.2 \mathrm{H}$ from top give considerable improvement in CBR value and stress strain behavior of sub grade soil.

\begin{abstract}
$>$ Choudhary A. K, Gill K. S and Jha J. N (2011) "Change in CBR estimations of far reaching soil sub grades utilizing geo synthetics," IGC J-233. set numerous layers of fortification on a level plane at indicated vertical dispersing inside the sub grade and subsequently deciding their relative positions for two unique kinds of support in particular geo grid and jute geo textile. The quantity of strengthening layers was differed from 1 to 4 . He found that the development proportion diminishes when the dirt is fortified with single layer and continues diminishing with increment in number of strengthening layer yet this decline is critical in the event of jute geo textile and peripheral if there should arise an occurrence of geo grid which implies inclusion of support controls swelling of soil. The CBR tests were led with both unreinforced and in addition fortified examples with shifting number of fortifying layers and support composes and found that the CBR estimation of the dirt likewise increments with increment in number of strengthening layers. Assist it was discovered that geo grid offer preferable fortifying productivity over jute geo textile however it can be profitably misused in minimal effort street venture.
\end{abstract}

$>$ Kumar Senthil and Rajkumar R (2012) "Impact of Geo textile on CBR Strength of Unpaved Road with Soft
Sub grade," EJGE Vol. 17 Fruitful utilization of geo synthetics is guaranteed in a given geotechnical application, as it isn't just perfect however viable in enhancing the dirt properties when fittingly put. In his investigation the execution of woven and nonwoven geo textile, interfaced between delicate sub grade and unbound rock in an unpaved adaptable asphalt framework, is done tentatively, using the California Bearing Ratio (CBR) testing game plan. Keeping in mind the end goal to assess the execution, the fortification proportion is acquired in view of the CBR stack - infiltration connection of both delicate sub grade-rock and delicate sub grade-geo textile-rock, independently, for woven and nonwoven geo textile. The impact of presenting geo textile layer between sub grade soil and base course layer and found that the protection from entrance increments with the presentation of geo textile layer. He utilized the condition given by (Koerner, 2005) for computing the fortification proportion i.e. loads with geo textile to stack without geo textile and found that the support proportion is more than one all through the test. Subsequently presumed that the utilization of geo textile is most focal points in street with delicate sub grade at higher entrance. However, the creator had played out the test basically on soil of class $\mathrm{CH}$ having a MDD of 1.562 also he has specified the woven and nonwoven geo textile yet he has not said the level of geo textile fortification neither its opening size and its thickness. Henceforth the outcomes are not approved.

$>$ Sujatha Evangelin Ramani and Jayaraman Vignesh (2012) "Improving the strength of sub grade using geo grids". GJRE VOL. 10,PP-233-239 provide geo grid reinforcement to improve the strength of sub grade and reduce the thickness of the pavement. The author conducted CBR tests on soil with geo grid introduced at different depths within the sample, in single, double and triple layer and found that the best performance in the single layer occurs when geo grid is placed at $2 / 3$ distance from the base. And found that the CBR value of 3 layer of geo grid is lesser than 2 layer but higher than single layer and hence concluded that geo grid increases the strength of sub grade soil in both soaked and un soaked condition and proved that geo grid reinforcement provided in a single or multilayer to the sub grade increases the strength of the soil and thus reduces the thickness of the pavement.

$>$ Singh Pradeep, Gill K. S (2012) "CBR Improvement of Vol.2 (315-318) Strengthened soils are frequently regarded as composite materials in with fortification opposing malleable pressure and communicating with soil through grinding. In spite of the fact that there is part of data and involvement with geo-manufactured support of sub-level soils, numerous asphalt disappointments still happen. These disappointments might be because of absence of comprehension of how these materials impact the designing properties of sub-review soils and what is the ideal position of support. Along these lines a compressive research facility program is required to contemplate quality attributes of both fortified and un-strengthened sub-review soils likewise to examine their practices under cycle driving. The creator in his work depicts the helpful impacts of strengthening the sub-review layer with a solitary layer of geo-lattice at various positions and accordingly assurance of ideal position of support layer. The ideal position was resolved in light of California Bearing Ratio (CBR esteem) and unconfined pressure tests were led to choose the ideal position of geo- 
framework. Through his test work he found that by giving geo grid fortification at $0.2 \mathrm{H}$ from top give extensive change in CBR esteem and stress strain conduct of sub grade soil.

$>$ Mihai Iliescu and Ioan Ratiu (2012) "Geo grid fortified street sub grade adjustment plan approach". EJGE VOL.15, PP-427-434 For subsoil with inadequate bearing limit, adjustment and change of subsoil attributes are important. The bearing limit can be expanded by uncovering and substitution of the delicate material, synthetic adjustment by utilizing chalk or by utilizing geo synthetics. Set between the sub grade and base course, or inside the base course, the geo synthetic enhances the execution of unpaved streets conveying channelized activity and unpaved zones subjected to arbitrary movement. They in their paper concocted another plan procedure for balancing out a street sub grade utilizing geo grid fortification. In their investigations, they discovered that geo grids can enhance the execution of the Sub grade soil. They did broad static and dynamic plate bearing tests on various conditions in light of the consequences of trial and the film hypothesis of Giroud and Noiray, they created configuration diagrams for multifunctional geo grids in unpaved and brief street.

$>$ M. Bagra (Aug 2013) In this, experimental learning was executed out on nearby existing (Doimukh, Itanagar, Arunachal Pradesh, India) soil with reinforcement of Jute fibres. Here soil samples were formulated at its MDD analogous to its optimal moisture content in CBR mould with and without reinforcement. Percentage of Jute fibre by dry weight of soil $-0.25 \%, 0.5 \%, 0.75 \%$ and $1 \%$ was taken. In the current investigation lengths of fibres were taken as $30 \mathrm{~mm}$, $60 \mathrm{~mm}$ and $90 \mathrm{~mm}$ and two dissimilar dia, $1 \mathrm{~mm}$ and $2 \mathrm{~mm}$ were considered for each fibre length. Test results indicate that CBR value of soil rises on inclusion of fibre content. It was also seen that on increasing diameter \& length of fibre further raises CBR value of reinforced soil and this rise is substantial at fibre content of $1 \%$ for $90 \mathrm{~mm}$ fibre length having diameter $2 \mathrm{~mm}$. Thus there is considerable rise in CBR value of soil with reinforcement of Jute fibre and this rise in CBR value will significantly reduce pavement sub grade thickness.

\section{Problem Identification}

> Black cotton soil has high swelling and shrinkage properties, it is hard as long as it remains dry, but it loses its stability when wet. on drying, the soil shrinks and cracks very badly.

$>$ Black cotton soil shrinks deep cracks develop when it is dry.

\section{Objective}

$>$ To study the effect of varying percentage of Stone Dust with sisal fiber on properties of Soil.

$>$ To study the combined effect of varying percentage of optimum quantity of Stone dust and optimum quantity of Sisal Fiber on properties of Soil.

\section{CONCLUSION}

$>$ The results of percentage increment in Un soaked CBR \& Soaked CBR goes on increasing with respect to Natural Soil when stone dust and sisal fiber is mixed.

\section{REFERENCES}

[1] AmbarishGhosh (2010) "Compaction characteristics and bearing ratio of pond ash stabilized withlime and phosphogypsum." Journal of Materials in Civil Engineering, ASCE, 343-351.

[2] Al-Rawas, A. A., Taha, R., Nelson, J. D., Al-Shab, T. B., and Al-siyabi, H., (2002), "A Comparative Evaluation of Various Additives Used in Stabilization of Expansive Soils", Geotechnical Testing Journal, Vol. 25, No. 2, pp. 199-209

[3] Bell, F. G. 1996. Lime Stabilization of Clay Minerals and Soils, Engineering Geology; 42: 223-237.

[4] Boominathan A, Ratna R. J. (1996) “Lime treated fly ash as embankment material." Proceeding of Indian Geotechnical Conference, Madras, India, 523526.oceeding of Indian Geotechnical Conference (IGC 96), Madras, 411-414

[5] ErdalCokca (2001) "Use of Class C Fly ashes for the stabilization of an Expansive soil." Journal of Geotechnical and Geo environmental Engineering, ASCE, Vol. 127, 568-573.

[6] Edil T. B., Acosta H. A., Benson C.H. (2006) "Stabilizing soft fine grained soils with fly ash." Journal of Materials in Civil Engineering, ASCE, Vol.18, 283-294.

[7] Fredlum D. G. \&Rahardjo H. (1993)"soil mechanics for unsaturated soils. John willy \& sons Inc. Newyork.

[8] Grim, R. E. (1968), Clay Mineralogy, 2nd edition, McGraw-Hill, New York.

[9] Ingles, 0. G., and J. B. Metcalf (1972) Soil stabilization principles and practice, Butterworth, Sydney, Australia.

[10] Kumar, S. and E. Tabor (2003) Strength characteristics of silty clay reinforced with randomly oriented nylon fibers. Electronic Journal of Geotechnical Engineering (EJGE).

[11] Maher, M. H. and Ho, Y. C. (1994), "Mechanical Properties of Kaolinite/Fiber Soil Composite", Journal of Geotechnical Engineering, ASCE, Vol. 120, No.8, pp.1381-1393.

[12] McGown, A. et al.(1978) Effect of inclusion properties on the behaviour of sand, Geo technique, 28(3), 327-346

[13] McGown, A., Andrawes, K. Z., Hytiris, N and Mercer, F. B. "Soil strengthing using randomly distributed mesh elements." Proc. 11th International Conf. on Soil Mechanics and Foundation Engg., San Francisco, Vol.3,(1985):pp.1735-1738

[14] Mitchell, J. K. and R. K. Katti (1981) Soil improvement .state-of-the-art report. Proc., 10th Int. Conf. on Soil Mechanics and Foundation Engineering. International 